\title{
Accuracy Assessment of Chow's Regression and Stochastic Methods for Estimating Instantaneous Peak Discharge (Case Study: Central Alborz Region)
}

\author{
Salajegheh, Ali \\ Faculty of Natural resources, University of Tehran, Kraj, Iran \\ Khosravi, Mohammad (Corresponding author) \\ Watershed Management, Faculty of Natural resources, University of Tehran, Kraj, Iran \\ Tel: 98-937-174-1237 E-mail: khosravim59@gmail.com \\ Mahdavi, Mohammad \\ Faculty of Natural resources, University of Tehran, Kraj, Iran
}

\begin{abstract}
In this research, accuracy of chow's regression and stochastic methods was analyzed for estimating instantaneous peak discharge in central Alborz region, Iran. Instantaneous peak discharges data in this region were incomplete, so we were used daily peak flood data for completing Instantaneous peak discharges using regression method. Finally 23 gauge stations with 20 years common data selected for analysis. Used 7 important frequency distributions including, Normal, two parameters Log Normal, three parameters Log Normal, Two parameters Gama, Pearson type three, Log Pearson type three and Gumbel. Then the best distribution was chosen to estimating instantaneous peak discharges for $2,5,10,15,20,25,30,50$ and 100 years return periods. Instantaneous Peak discharges for above return periods were estimated using chow's regression and Stochastic methods, and were compared with the best fitted distributions results using probabilities indices such as MSE and MBE. Our results showed that chow's regression method is better than stochastic method for estimating instantaneous peak discharge in central Alborz region.
\end{abstract}

Keywords: Chow's regression method, Stochastic method, Time series, Instantaneous peak discharge, Central Alborz region, Iran

\section{Introduction}

Flood is an unusual high stage of river that overflows the natural or manmade banks spreading out to its flood plains that are thickly populated due to the obvious advantage of water supply and irrigation. The estimation of peak flow of a design return period is a standard requirement in many civil engineering projects such as design of bridge openings and culverts, drainage networks, flood relief/protection schemes and the determination of flood risk and 'finish-floor level' for both commercial and large-scale residential developments (Keshav P. Bhattara 2005).

The first information required to predict floods with specific return periods are flood recorded in gauge stations (K.C.Patra 2001). There are several methods for flood prediction using recorded data such as Normal, Two parameters log Normal, three parameters log Normal, Two parameters Gama, Pearson type three, log Pearson type three and Gumbel method. Chow's regression and stochastic methods have been simplified in such a manner that one can obtain the magnitude of a given return period flood without recourse to looking at tables and working out the value of the coefficient of variation of the given data. Type I extreme-value distribution, the first asymptotic distribution (Gumbel, 1958), has two parameters, but it has a fixed skew of 1.139 and therefore is not symmetrical about the mean. Use of this distribution for annual floods was proposed by Gumbel (1941). Powell (1943) prepared the plotting paper based on this distribution. The mean of the distribution occurs at the 2.33-year recurrence interval when the distribution is cumulated from the upper end. Accuracy of Chow's regression (Gumbel modified method) and Stochastic methods compared in this research for estimating instantaneous peak discharge with comparing the best fitted distribution in central Alborz region, Iran. G.Almashidani et.al (1978) compared three methods of Gumbel, Powell modification and Chow's regression method for estimating instantaneous peak discharge in 7 Iraqi rivers and showed that for five out of the seven Iraqi rivers, the prediction by the chow's regression method compares favorably with those of Gumbel and Powell. For two rivers, however, the Greater Zab at Eski-Kelek and the Adhaim at the Narrows, the chow's regression method gives values approximately 10 per cent higher than those of Gumbel. Indian ministry of development of northeastern region (2006) at study research in Chenab River for building a reservoir dam used 27 years of annual flood recorded data. Results showed that chow's regression method gives values more than Gumbel method in all of return periods. Johannes Devries (2006) showed that stochastic modeling gave lower flood estimates than frequency-based analyses. Maarofi (2003) showed that Gumbel method is the best-fitted distribution in 10 regions of Hamadan province. Arab khedri (1988) showed that log Pearson type 3 is the best-fitted distribution in North Alborz catchments. 


\section{Materials and Methods}

\subsection{Study Area}

The study was conducted in Tehran, Qazvin, Semnan and Mazandaran provinces. The study area was bounded by $52^{\circ}-46^{\prime}$ to $50^{\circ}-03^{\prime} \mathrm{E}, 35^{\circ}-12^{\prime} \mathrm{N}$ to $36^{\circ}-20^{\prime} \mathrm{N}$ (Fig. 1 ). The different land uses in stusy area are shown in Table.1.

\subsection{Data}

After data exploration, 23 hydrometric stations with 20-yr common data were selected. The characterestics of selected stations are shown in Table.2.

\subsection{Methodology}

After data exploration, 23 hydrometric stations with 20-yr common data were selected. The observed data in each station divided into time series of 10, 15 and 20 years. We obtained 11 series of $10-y r, 6$ series of $15-y r$ and one serial of $20-\mathrm{yr}$ in each gauge station. Investigation of data trends obtained using of mann-kendall trend test. Using HYFA, we found the best-fitted distribution for each time series. In order to assess the performances and accuracy of chow's regression and Stochastic methods for estimating instantaneous peak discharge in the case study region compared the estimated data by mentioned methods with the best-fitted distributions. In addition to assess errors of methods we were used probability indices such as mean square error (MSE) and mean bias error (MBE). The first probability index shows accuracy of methods and the second one shows the course of error. finally the results of the methods assessed using SPSS software with ANOVA $(p=0.05)$. for investigation the trend of data used mann-kendal trend test.

1) Chow's regression method

Chow proposed a linear equation of the form

$Q_{t}=a+b x_{t}$

Where $a$ and $b$ are the regression constant, $Q_{t}$ is the flood of return period T years and $x_{t}$ is given as

$$
x_{t}=\log \log \left\{\frac{T}{(T-1)}\right\}
$$

By the method of least square, the constant $\mathrm{a}$ and $\mathrm{b}$ can be computed as

$$
\begin{aligned}
& \sum Q_{t}=a N+b \sum x_{t} \\
& \sum Q_{t} x_{t}=a \sum x_{t}+b \sum x_{t}^{2}
\end{aligned}
$$

And when the data are arranged in decreasing order, the return period $t$ is given as ${ }_{T=\frac{(N+1)}{m}}$

Substituting $\mathrm{T}$ in Equation (2) the value of $x_{t}$ is obtained as

$x_{t}=\log \left[\log \left(\frac{(N+1)}{(N+1-m)}\right)\right]$

The above equation is solved to get $Q_{t}$ of the desired return period (K.C.Patra 2001).

2) Stochastic method

A well known equation for computation of instantaneous peak discharge using probability law is written the form

$Q_{t}=Q_{\min }+2 / 303\left(Q_{a v e}-Q_{\min }\right) \log \left(\frac{n T}{N}\right)$

The equation used the theory of sums of random numbers where $\mathrm{T}=\mathrm{N} / \mathrm{m}$ which is the California plotting position formula, $\mathrm{n}$ the number of recorded floods which assigns only one value to the same event and $\mathrm{N}$ total of data. $Q_{\text {min }}$ is the minimum value of floods in the series, $Q_{a v e}$ is the average of series and $Q_{t}$ is the flood of return period t years(K.C.Patra 2001).

3) Mean square error (MSE)

This probability index is given as

$M S E=\frac{\sum_{i=1}^{n} S E_{i}}{n}$

In this equation $\mathrm{n}$, is number of data and $\mathrm{SE}_{\mathrm{i}}$ is given as

$\mathrm{SE}_{\mathrm{i}}=\left(\mathrm{Q}_{\mathrm{oi}}-\mathrm{Q}_{\mathrm{ci}}\right)^{2}$

$\mathrm{Q}_{\mathrm{oi}}$ is observed instantaneous peak discharge(estimated data with the best fitted method), $\mathrm{Q}_{\mathrm{ci}}$ is estimated instantaneous peak discharge using Chow's regression method or Stochastic method. 
4) Mean bias error (MBE)

This probability index is given as

$M B E=\frac{\sum\left(Q_{s}-Q_{o}\right)}{n}$

$\mathrm{Q}_{\mathrm{oi}}$ is observed instantaneous peak discharge(estimated data with the best fitted method), $\mathrm{Q}_{\mathrm{ci}}$ is estimated instantaneous peak discharge using Chow's regression method or Stochastic method.

\section{Results}

For known the best method in estimating instantaneous peak discharge their results assessed using SPSS software with ANOVA $(\mathrm{p}=0.05)$. Results showed that both methods estimations have non-significant difference in comparison with best-fitted distributions in all series and return periods. The regional data showed a trend using mann-kendall method (Table .2). MSE and MBE obtained in basis of described methodology in every series and return periods of 2,5,10,15,20,25,30,50 and 100 years. Results showed that Stochastic method in comparison with the best fitted distribution underestimated in 10-yr time series for return periods of 2, 50 and 100 years, and overestimated in another return periods. In this series Chow's regression method results were underestimated in return periods of 50 and 100 years and overestimated in other return periods. Stochastic method in comparison with the best fitted distribution in 15-yr time series overestimated in all return periods except 2 years return period and Chow's regression method in this series overestimated for all of return periods. In 20-yr time series underestimated for return periods of 2, 30, 50 and 100 years and overestimated in other return periods. Chow's regression method in this time series underestimated for return periods of 30, 50 and 100 years, and overestimated for another return periods. Stochastic method in comparison with Chow's regression method had better estimations in return period of 5-yr in all of time series. In addition, this method in time series of 10 and 15 had better estimations for return period of 10 year. Except these return periods in other return periods and all time series Chow's regression method had better estimations than Stochastic method. In upper return periods, both methods had less certitude than lower return periods. The reason can be incommensurate long time of data with upper return periods estimated. The MSE results for both methods showed in Fig.2 to Fig.4 and MBE results showed in Fig.5 to Fig.7.

\section{Discussion}

In time series of 10-yr, Hable-Rood station was the only one station that Stochastic method gave best results than Chow's regression method and in other 22 stations Chow's regression method instantaneous peak discharge estimations were better than Stochastic method. In time series of 15-yr, there were three stations with best fitted distribution of Two parameters Gama, in these stations Stochastic method had more accuracy than chow's regression method. Also in this time series in stations of Roodak (with Gumbel dominanat distribution), Namrood (with Pearson type three dominanat distribution) and Latian (No dominant distribution) the Stochastic method had more accuracy than Chow's regression method and in other stations Chow's regression method gave better results than Stochastic method. in time series of 20 -yr there were 6 stations with best fitted distribution of three parameters Log Normal. In four of them, accuracy of Stochastic method for estimating instantaneous peak discharge was more than Chow's regression method and in other stations it was inverse. In order to investigation of best fitted distribution results showed that three parameters Log Pearson had the highest frequency in all time series. So in most of studied stations Chow's regression method is better than stochastic method for peak flood estimation. Also in this region three parameters Log Pearson had more percent as the best fitted distribution. It shows that Chow's regression method is more reliable than Stochastic method where the fitted distribution is three parameter Log Pearson. In stations where two parameters Gama and three parameters Log Normal distributions are best fitted distributions, it seems that Stochastic method has more precision than Chow's regression method, but it needs more researches.

\section{Conclusion}

This research was the first one for assessment the mentioned methods in Iran. Our results showed that the used methods and specially Chow's regression method can be used as a practical method for estimating instantaneous peak discharges in study area.

\section{References}

Arabkhedri, M. (1990). Assessment of peak floods in North Alborz watersheds, M.S.C thesis, faculty of Natural resources, University of Tehran.

G. AL-MashidaniI, Pande, B.L al and M. F attah Mujda. (1978). A simple version of Gumbel's method for flood estimation, Hydrological Sciences-Bulletin-des Sciences Hydrologiques.

Gumbel, E. J. (1941). the return period of flood flows: Annals Math. Statistics v. 12, no. 2, p. 163-190.

Gumbel. (1958). Statistics of extremes: New York, Columbia Univ. Press, 375 p.Hazen, Allen, 1930, Flood flows, a study of frequencies and magnitudes: New York, John Wiley \& Sons,Inc.

H. C. Riggs. (1989). Techniques of Water-Resources Investigations of the United States Geological Survey, Chapter A2, Frecuency curves. 
Johannes Devries. (2006). Comparing Statistical Approaches to Estimating Floods, David Ford Consulting Engineers 2015 J St., Suite 200 Sacramento, CA 95814.

Keshav P. Bhattara. (2005). Flood frequency analysis of Irish river flow data using variants of L-Moment, National Hydrology Seminar.

Mahadavi, M. (2003). Applied hydrology, Tehran university, fourth edition, Vol. 1.

Marofi. (2003). Investigation of the probability distributions fitting to extreme values of flood, Geophysical Research Abstracts, Vol. 5.

Ministry of development of north eastern region, India. (2006). A fluvial geomorphology perspective on the knowledge base of the Brahmaputra, Background Paper NO. 3.

Patra K.C. (2001). Hydrology and Water Resource Engineering, Alpha science International Ltd, pages 410-430.

Powell, R. W. (1943). a simple method of estimating flood frequencies: Civil Eng., v. 13, no. 2, p. 105-106.

Table 1. Area and Percentage of Different Land Uses in study area

\begin{tabular}{|c|c|c|}
\hline Land use Type & Area ( Ha ) & Area (\%) \\
\hline Range & 1146585 & 61.3 \\
\hline Irrigated land & 350355 & 18.7 \\
\hline Rainfed land & 28435 & 1.5 \\
\hline Scattered rainfed & 55905 & 3 \\
\hline Rock Outcrops & 99080 & 5.3 \\
\hline Saline land & 56305 & 3 \\
\hline Bare lands & 59575 & 3.2 \\
\hline Urban & 70625 & 3.8 \\
\hline Afforestation & 435 & 0.02 \\
\hline Total & 1870300 & 100 \\
\hline
\end{tabular}

Table 2. stations, drainage area and mean annual precipitation

\begin{tabular}{|c|l|c|c|}
\hline Rank & Hydrometrical Station & Drainage area $\left(\mathrm{km}^{2}\right)$ & $\begin{array}{c}\text { Mean annual Precipitation } \\
(\mathrm{mm})\end{array}$ \\
\hline 1 & Galinak & 775 & 452 \\
\hline 2 & Darbande fashan & 35 & 456 \\
\hline 3 & Dehe somea kurdan & 360 & 500 \\
\hline 4 & Dehe somea kanal & 80 & 350 \\
\hline 5 & Bailaghan & 1048 & 645 \\
\hline 6 & Solaghan & 196 & 535 \\
\hline 7 & Rodak & 421 & 671 \\
\hline 8 & Narvan & 30 & 675 \\
\hline 9 & Latian & 710 & 455 \\
\hline 10 & Haft hoz & 82.5 & 480 \\
\hline 11 & Pole siman fazelab & 92 & 250 \\
\hline 12 & Sharif abad & 105 & 135 \\
\hline 13 & Simindasht & 2064 & 200 \\
\hline 14 & Firoozkooh & 581 & 380 \\
\hline 15 & Namrood & 587 & 320 \\
\hline 16 & Gachsar & 207 & 813 \\
\hline 17 & Sira & 725 & 710 \\
\hline 18 & Barajin & 250 & 400 \\
\hline 19 & Bonkooh & 210 & 195 \\
\hline 20 & Poloor & 45 & 450 \\
\hline 21 & Dalichay & 32 & 505 \\
\hline 22 & Ghabl az cheshmeha(lar) & 60 & 510 \\
\hline 23 & Bad az cheshmeha(lar $)$ & 75 & 500 \\
\hline
\end{tabular}


Table 3. Regional Mann-Kendall Test for Trend

\begin{tabular}{|l|l|}
\hline record & 20 years (from 1986-2005) \\
\hline Y & 23 \\
\hline the tau correlation coefficient & -0.150 \\
\hline $\mathrm{S}$ & -656. \\
\hline $\mathrm{Z}$ & -4.432 \\
\hline $\mathrm{P}$ & 0.0000 \\
\hline Stations number & -0.4500 per year \\
\hline
\end{tabular}

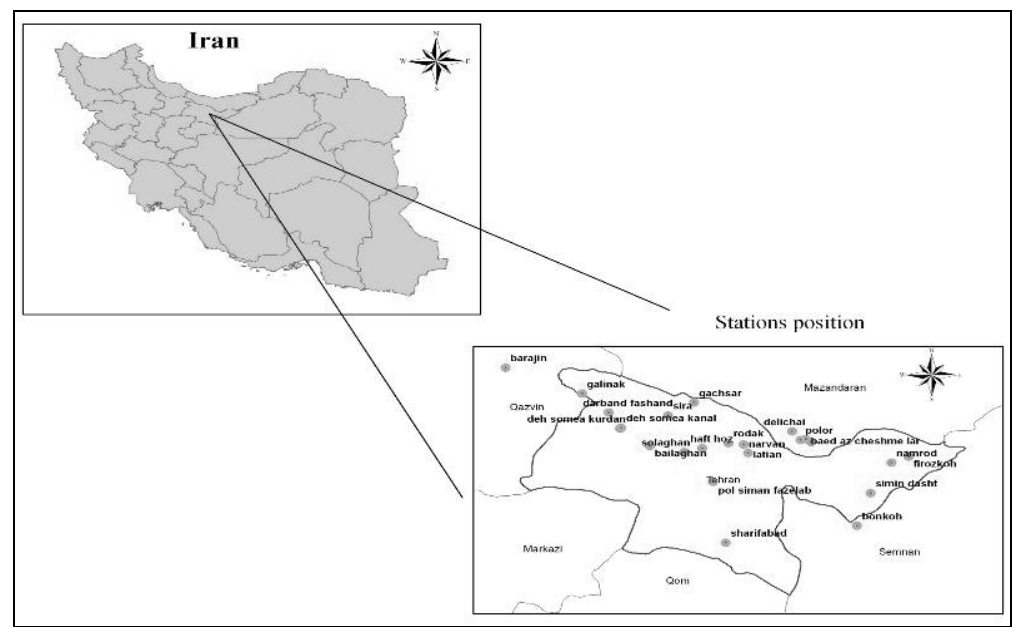

Figure 1. Map of study area and hydrometrical stations position

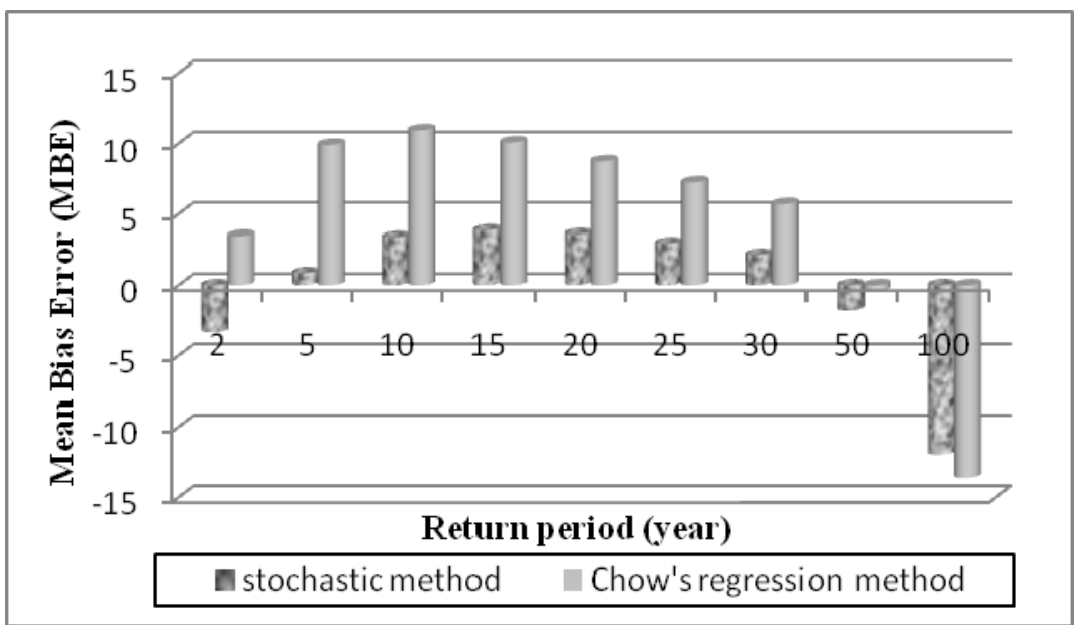

Figure 2. Comparison of MSE in 10 years time series 


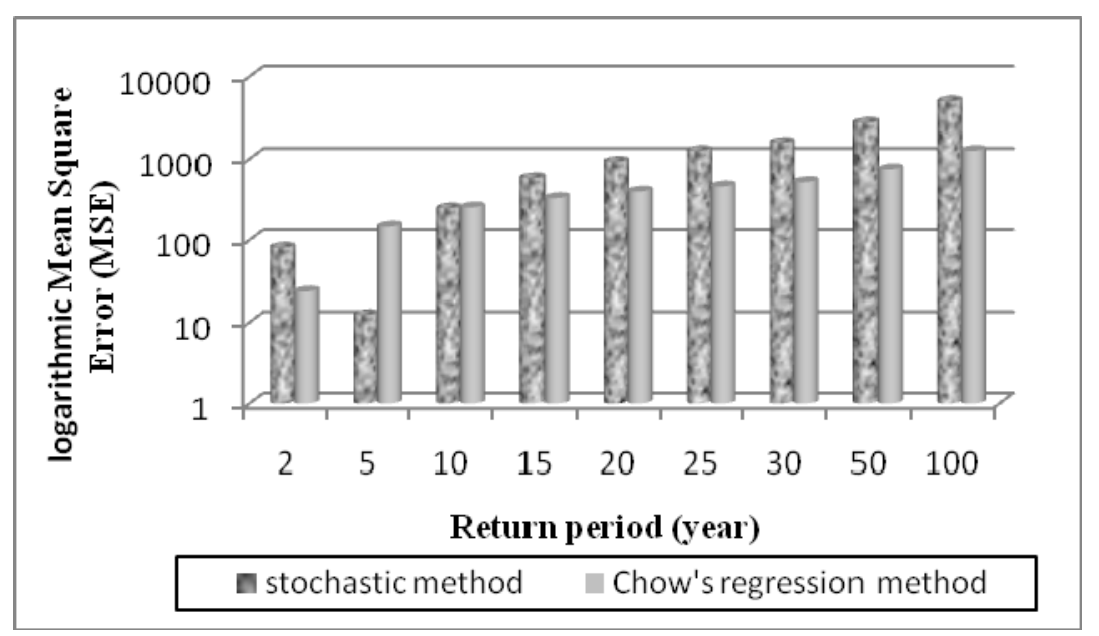

Figure 3. Comparison of MSE in 15 years time series

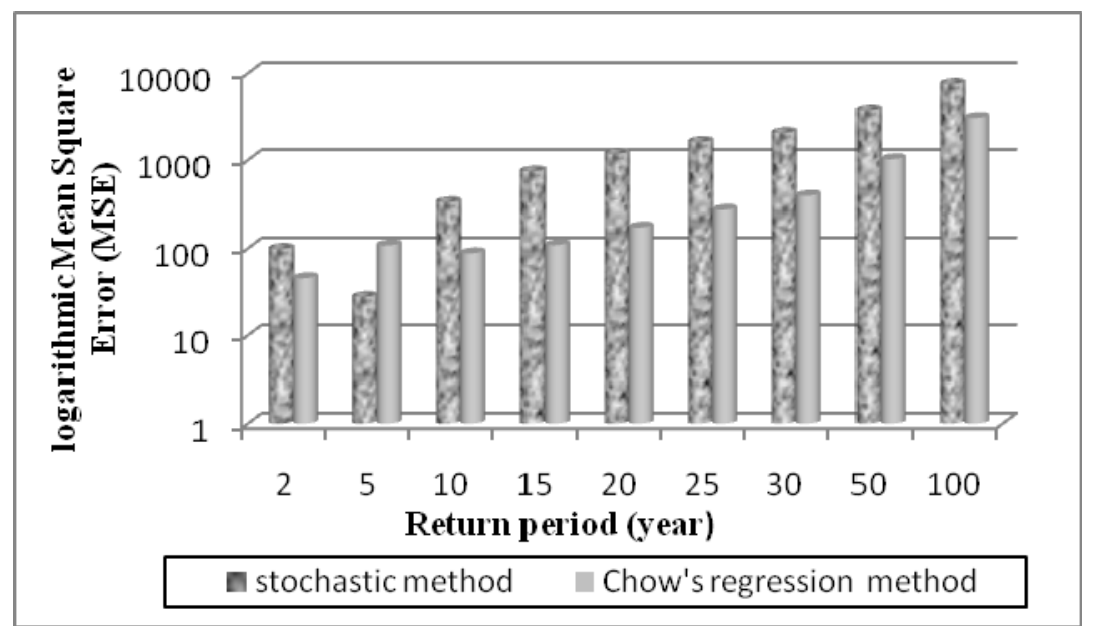

Figure 4. Comparison of MSE in 20 years time series

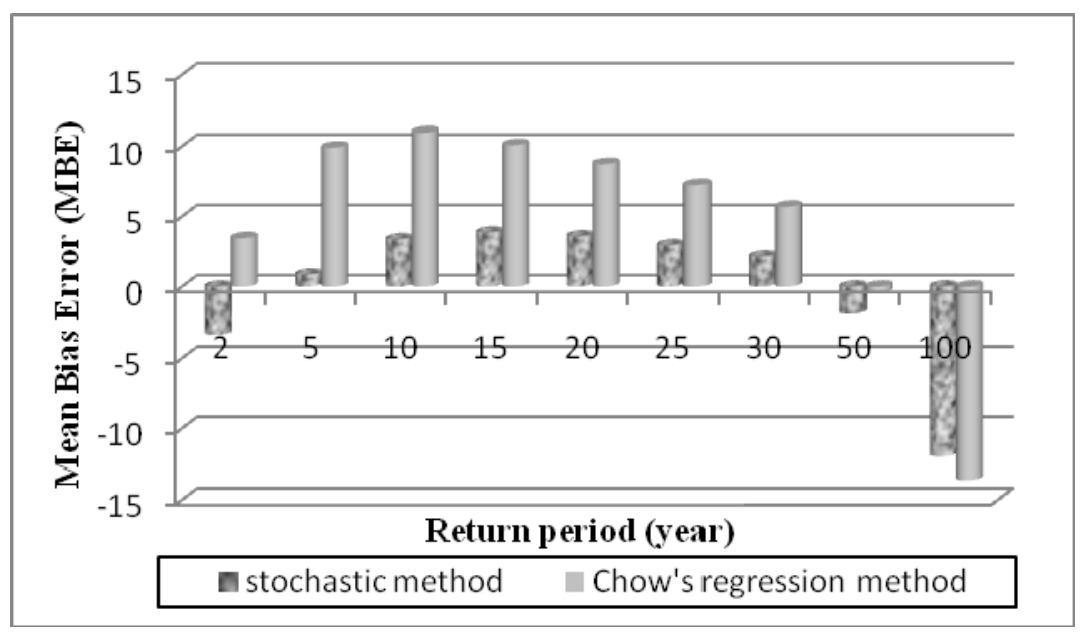

Figure 5. Comparison of MBE in 10 years time series 


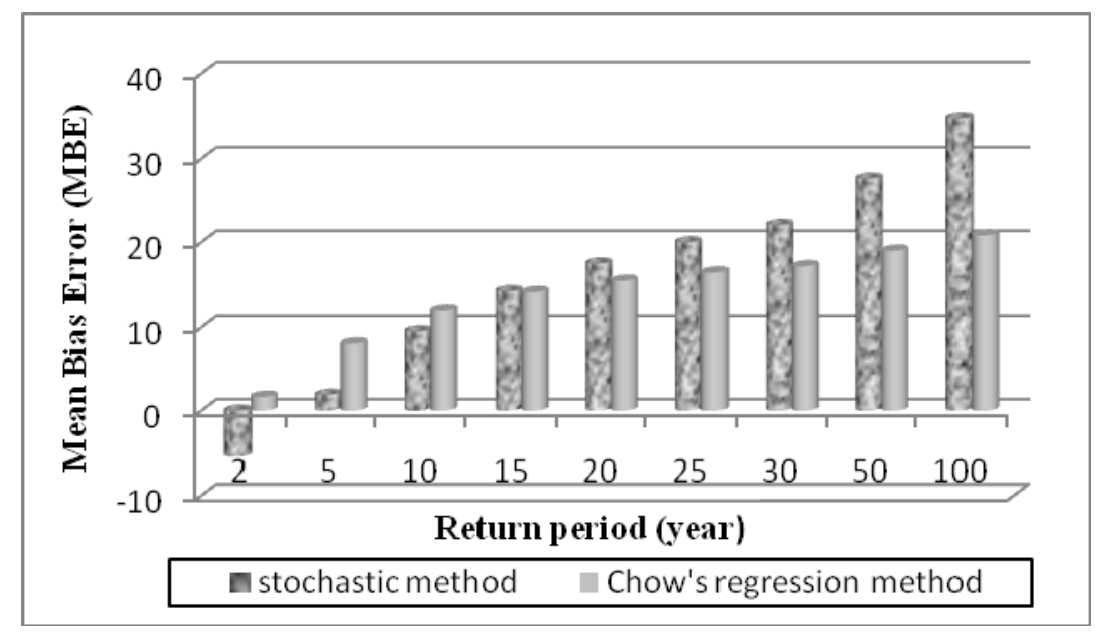

Figure 6. Comparison of MBE in 15 years time series

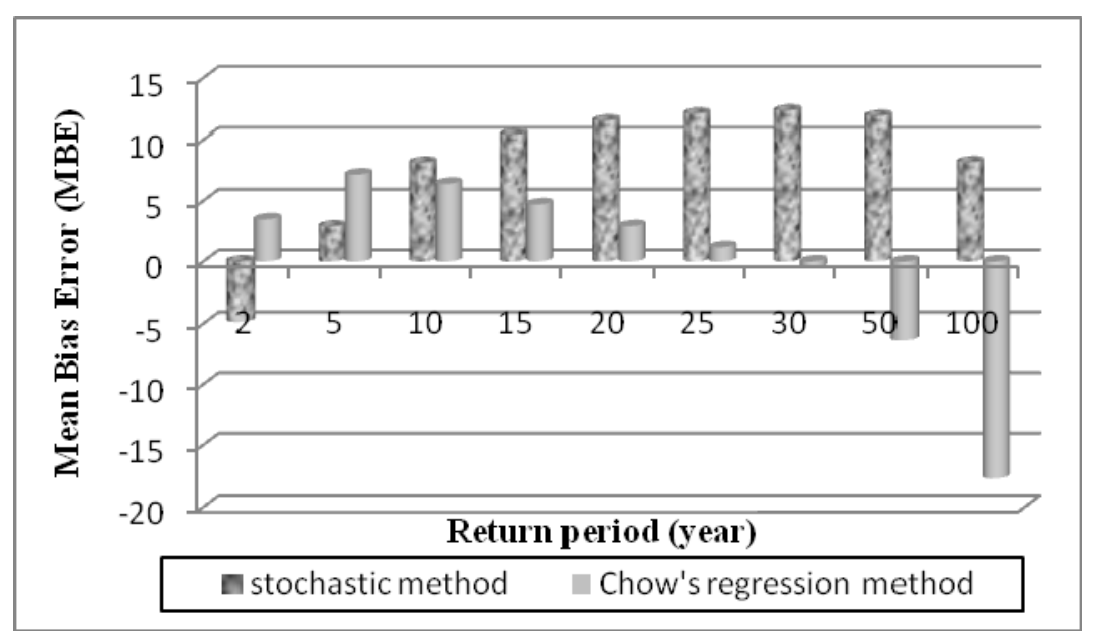

Figure 7. Comparison of MBE in 20 years time series 